\title{
Research and application of intelligent teacher evaluation system of private universities in China
}

\author{
Yang Bo ${ }^{1, a}$, Zhang Li-na ${ }^{2, b^{*}}$ \\ ${ }^{1}$ Changchun University of Finance and Economics, Changchun, Jilin, 130122, China \\ 2 Jilin Agricultural University, Changchun, Jilin, 130118, China \\ amail_yangbo@163.com, ${ }^{\mathrm{b}}$ mail_zhangln@163.com
}

Keywords: private universities in China, index of teacher evaluation, intelligent evaluation, experimental prediction

\begin{abstract}
China's private universities as a supplement to public education, in recent years, rapid development, and continuously improve the strength of school. The internal management of private colleges and universities has its own characteristics, the subject of education is the students and teachers, and the management of teachers is the main body, private university teachers are more than a combination of part-time, this mechanism makes the quality and ability of teachers is uneven, it is difficult to evaluate. In this paper, the artificial intelligence theory is applied to the evaluation system of private university teachers, and the index of evaluation is set up according to certain requirements and use sample data to test. Through the comparison of the various nuclear functions and parameters of the SVM method, the SVM method is proved to fit the teacher evaluation system. The application of SVM method makes the evaluation more accurate and reasonable, and reduces the workload of the teaching management department, and reduces some errors caused by human error.
\end{abstract}

\section{Introduction}

Intelligence teacher evaluation System is the use of computer-based artificial intelligence field related disciplines (such as neural networks research networks, Support Vector Machine, etc.) and data mining has been made to study the teacher evaluation issue, combined with expert knowledge and experience and machine learning in the field to Evaluate the ability of teachers. In this way, we can not only analysis and evaluate to teachers' comprehensive ability, as well as can be measured and evaluated a number of other phenomena in the field of education. Certain extent, can promote the development of educational measurement and educational research.

\section{Present situation of teachers in private universities in China}

In recent years, the development of private higher education in China has grown, and private universities have sprung up, and different forms and different types of private schools have been established, this form of education has been industrialized, market-oriented, so that in the education and teaching management and other aspects of the forefront of public schools. There are many factors affect the private university, be too numerous to enumerate, but the teachers quality and stability is a key problem. It has been plagued by the development of private universities.

Teaching quality is the lifeline of higher education, good teaching quality and social reputation can guarantee the sustainable development of the school. Teachers are the core of improving the quality of teaching, because of the difference between public schools and private universities, the main performance is the obstacle of different systems, followed by the performance of private university internal measures are not effective, the teacher evaluation leads to the loss of a large number of teachers lose the sense of propriety. Teachers' resources are always limited, if public schools recruit to a teacher, and this teacher is a good teacher, then, a private school will be less a good teacher. At the same time, excellent teacher talent will always choose to go to public schools, because there is a good treatment, teaching and scientific research environment. The institutional 
weaknesses, it hinders the stability of teachers in private colleges and Universities. At the same time, the sources of private university teachers are more complex, and the relationship between the part-time teachers is not enough, the experienced teachers are public school retirees, most teachers are from the community to recruit teachers, most of the teachers lack the experience of teacher training and classroom theory teaching, some teachers teaching scientific research ability and quality is relatively low. Some private universities in charge, to teachers in the evaluation, evaluation, evaluation of professional titles and the promotion ability work seriously enough, which hinder the private school teachers of normal and stable development.

For private universities, they should implement a special promotion assessment system, strengthen the continuing education training, the introduction of competition incentive mechanism, research for the evaluation system of China's private universities, make the reasonable and scientific evaluation of Teachers, this has a direct impact on the investment and the value orientation of the teacher to the teaching and academic research, to a large extent to the work of the school to play a positive role.

\section{Index of teacher evaluation}

Chinese teacher evaluation roughly divided into two categories:

Incentives and penalties of teacher evaluation, it is the ultimate goal of reward and punishment, through the evaluation of teachers' performance, to check the qualifications and competence of teachers, It provides personnel decisions summative based on the retention, promotion, pay, dismissal of teachers, etc. Development of teacher evaluation is a formative evaluation, it does not aim to reward and punishment, promote professional development of teachers in the absence of reward and punishment conditions. Teacher evaluation in order to promote the development of teachers' professional development is the ultimate goal. It considered internal motivation than the external pressure has a greater incentive for teachers, the better educated teachers are mainly self-motivation. External pressure can make them meet minimum standards, to achieve the level of excellence, but also on the internal dynamics.

In this paper, we research the evaluation index and the weight of each part of the private university, and consider whether the evaluation index has a great impact on the teacher evaluation. The intelligent evaluation system does not need to be in strict accordance with the weight of each index of the teachers, because through intelligent learning, the weight of each index will be obtained by artificial intelligence, therefore, it is only a need to research which indicators are suitable for the evaluation of private universities in China.

To sum up, the evaluation system for private university teachers should establish a perfect index system. According to the actual situation of teacher development evaluation system, the evaluation index system of fuzzy comprehensive evaluation is established from the perspectives of representation, system and applicability, the fuzzy evaluation matrix of the relative membership degree of the evaluation index unit is established by the sample data of the evaluation index.

The evaluation index system of this paper is composed of three dimensions:

$>$ Index I: For the evaluation of teachers will have to study aspects, namely a big classification, every I class contains a number of sub index.

$>$ Index II: Index I refinement of several sub index.

$>$ Index III: Content and standard of evaluation.

According to the characteristics of private university teachers in China, the evaluation index system is established, due to space, some representative indexes are described, as shown in the table 1. 
Table1. Index of teacher evaluation

\begin{tabular}{|c|c|c|}
\hline Index I & Index II & Index III \\
\hline \multirow{3}{*}{ Teaching } & Teaching workload & The number of hours required by teachers to complete \\
\hline & Teaching quality & $\begin{array}{l}\text { Good teaching effect, cultivate the ability to solve practical } \\
\text { problems with the application of knowledge }\end{array}$ \\
\hline & $\begin{array}{c}\text { Teaching } \\
\text { achievement }\end{array}$ & $\begin{array}{l}\text { Novelty, practicality, to improve teaching level and } \\
\text { education quality }\end{array}$ \\
\hline \multirow{3}{*}{$\begin{array}{l}\text { Scientific } \\
\text { research }\end{array}$} & Research project & The number and level of the project to host or participate. \\
\hline & $\begin{array}{l}\text { Published papers } \\
\text { and books }\end{array}$ & $\begin{array}{c}\text { The number of papers published, the number of books and } \\
\text { papers }\end{array}$ \\
\hline & $\begin{array}{l}\text { Scientific research } \\
\text { achievements }\end{array}$ & Get different levels of research awards \\
\hline
\end{tabular}

\section{Intelligent evaluation}

The evaluation method of artificial intelligence is a lot of methods, this paper selects the method of education evaluation based on SVM. Support Vector Machine (SVM) is built on the VC dimension theory of the basis of statistical learning theory and structural risk minimization principle, It find the best compromise based on the limited sample of information in the model complexity (Learning accuracy for specific training samples) and learning ability (The ability to identify any error of samples). Research on SVM was originally aimed at pattern recognition II linearly separable problems, it evolved from the optimal classification surface of linearly separable case, and we need to use the following functions

Find $\alpha_{i}$ maximum value for the following functions:

$\mathrm{Q}(\alpha)=\sum_{i=1}^{n} \alpha_{i}-\frac{1}{2} \sum_{i, j=1}^{n} \alpha_{i} \alpha_{j} y_{i} y_{j}\left(x_{i} \cdot x_{j}\right)$

Support Vector: $\alpha_{i} \neq 0$, and $\mathrm{y}_{i}\left(w \cdot x_{i}+b\right)-1=0, x_{i}$ is support vectors at this point.

Non-Support Vector: $\alpha_{i}=0$, and $y_{i}\left(w \cdot x_{i}+b\right)-1>0, x_{i}$ is not support vectors.

Finally, the classification function of the optimal classification surface is formula 2:

$f(x)=\operatorname{sgn}\left\{\sum_{i \in S V} \alpha_{i}^{*} y_{i}\left(x_{i}, x\right)+b^{*}\right\}$

In many issues need to be extended to non-linear classification surface, for nonlinear problems, the input samples are mapped into a high dimensional feature space $\mathrm{H}$, Using the kernel function to solve the problem. Appropriate inner product function $K\left(x_{i}, x_{j}\right)$ in the optimal classification surface, it can achieve linear classification after non-linear transformation, and do not increase the computational complexity, at this time the dual objective function in the form formula 1 becomes formula 3:

$\mathrm{Q}(\alpha)=\sum_{i=1}^{n} \alpha_{i}-\frac{1}{2} \sum_{i, j=1}^{n} \alpha_{i} \alpha_{j} y_{i} y_{j} K\left(x_{i} \cdot x_{j}\right)$

While the corresponding classification function also becomes formula 4 :

$f(x)=\operatorname{sgn}\left\{\sum_{i \in S V} \alpha_{i}^{*} y_{i} K\left(x_{i} \cdot x\right)+b^{*}\right\}$

\section{Experimental prediction}

This paper chooses 3 private universities which have certain strength in northern China as an experimental school, and got teacher evaluation data. According to the evaluation index system, the paper makes some changes to the default index of the teacher evaluation system. Because the intelligent evaluation system based on SVM needs to train the system model, and set the parameters, so the teacher data is divided into two parts, which will be about $35 \%$ of the data as a training sample set, the remaining $65 \%$ of the data as the forecast sample to be evaluated.

In model training and prediction, first of all need to be in a set of sample data pretreatment, in 
addition to the transformation of vector data on teacher evaluation, but also the data are normalized. As shown in Table 2, part of the data for the normalization process.

Table2. Normalized data

\begin{tabular}{|c|c|c|}
\hline Category & Original evaluation vector & Normalized evaluation vector \\
\hline 0 & 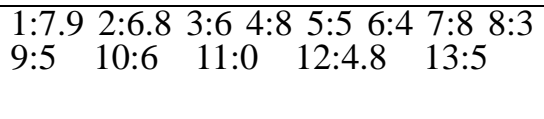 & 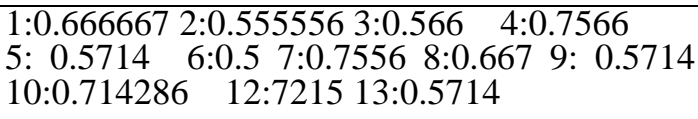 \\
\hline 1 & 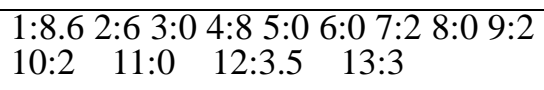 & $\begin{array}{l}\text { 1: } 0.78552 \text { 2:0.714286 4:0.5453 7: } 0.666667 \\
\text { 10: } 0.365512: 0.1333 \quad 13: 0.285714\end{array}$ \\
\hline \multicolumn{3}{|c|}{$\cdots \cdots \cdots$} \\
\hline 4 & 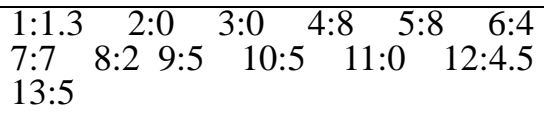 & $\begin{array}{lcccc}1: 0.276596 & 4: 0.666667 & 5: 1 & 6: 0.5 & \\
7: 0.857143 & 8: 0.4 & 9: 0.5 & 10: 0.5714 & 12: 0.8 \\
13: 0.571 & 14: 1 & 15: 0.5555 & 16: 0.666 & 18: 0.5\end{array}$ \\
\hline
\end{tabular}

In this paper, support vector machine and K-means algorithm were compared, using the same sample data sets to train and predict. Using RBF kernel function in SVM, Cluster centers is 4 for K-Means. The prediction accuracy of the comparison results on two methods, as shown in Table 3.

Table3. The prediction accuracy of the SVM and K-Means

\begin{tabular}{|l|l|l|}
\hline Classification & Parameter & accuracy \\
\hline SVM & RBF kernel function, C=25, $\gamma=0.065$ & $95.625 \%$ \\
\hline K-Means & The number of initial cluster centers 4 & $87.528 \%$ \\
\hline
\end{tabular}

The experimental results show that there is a certain error in the classification of the $\mathrm{K}$ - mean method, and the accuracy rate is $\mathbf{8 7 . 5 2 8 \%}$. The support vector machine can generate the model file by training sample data, and it is not required to know the number of the forecast data. Support vector machine in the accuracy of the cross validation is better than the $\mathrm{K}$ - method, the accuracy rate was $95.625 \%$ when the experimental setting parameters $C=25$ and $\gamma=0.065$.

\section{Summary}

In this paper, support vector machine theory is introduced into the evaluation of private university teachers, according to the characteristics of Chinese private universities to establish the evaluation system and evaluation index for the characteristics of private schools in China. Intelligent teacher evaluation system is the result of objective, fair and practical significance, but also practical strong. The results of SVM method are objective and stable. Combined with the fuzzy comprehensive evaluation method, the complex problem of the teacher evaluation is solved well. Experiments show that this method has good application value and popularization.

\section{Acknowledgments}

This work was financially supported by the Science and Technology Research Project of the Education Department of Jilin Province (2014-B057) and the Jilin Province Education Science “Twelve-Five” planning issues (ZD15173).

\section{References}

[1] Christopher M. Clark and Frances O'C. Rust, LEARNING-CENTERED ASSESSMENT IN TEACHER EDUCATION,Studies in Educational valuation, 2006,32: 73-82. 
[2] Dominique M.A. Sluijsmans, Saskia Brand-Gruwel,Jeroen J.G. van Merrignboer, and Theo J. Bastiaens,THE TRAINING OF PEER ASSESSMENT SKILLS TO PROMOTE THE DEVELOPMENT OF REFLECTION SKILLS IN TEACHER EDUCATION,Studies in Educational Evaluation, 2003,29: 23-42.

[3] LI Honglian,WANG Chunhua,YUAN Baozong, An Improved Support Vector Machines: NNSVM,Chinese Journal of Electronic, 2004,13(2):72-80. [19] Li Changkui,Jiang Chengyu,Wang Ningshen,A Fast Algorithm for Support Vector Clustering, Journal of Southwest Jiaotong University, 2004,12(2).

[4] SUN Jin-wen,YANG Jian-wu,LU Bin,XIAO Jian-guo,Incremental Training for SVM-Based Classification with Keyword Adjusting,Wuhan University Journal of Natural Sciences, 2004(19):5.

[5] Vapnik N, Levin E, Le Cun Y,Measuring the VC-dimension of a learning machine [J],Neural Computation, 1994,6(5):851-876.

[6] Wiskott L., Fellous J.-M. Krilaer N.,von der Malsburg C., Face recognition by elastic bunch. matching[J],IEEE Trans. on Pattern Analysis and Machine Intelligence,1997,19(7): 775-779.

[7] Matic N,Guyon I,Denker J et al. Writer adaptation for on line handwritten character recognition. 2nd Intl. Conf. on Pattern Recognition and Document Analysis,1993,187-191.

[8] Donald Christie,THE STANDARD FOR CHARTERED TEACHER IN SCOTLAND:A NEW CONTEXT FOR THE ASSESSMENT ANDPROFESSIONAL DEVELOPMENT OF TEACHERS, Studies in Educational Evaluation,2006,32:53-72.

[9] Osuna E, Freund R, Girosi F. Training support vector machines: an application to face detection. Proc. of CVPR'97,Puerto Rico, 1997.

[10] C. Burges,A tutorial on support vector machines for pattern recognition. Data Mining and Knowledge Discovery, 1998,2,121-167. 